\title{
Improving Tornado Warning Communication for Deaf and Hard of Hearing Audiences
}

\author{
JASON C. SENKBEIL \\ Department of Geography \\ University of Alabama, Tuscaloosa, Alabama \\ DARRIN J. GRIFFIN \\ Department of Communication Studies \\ University of Alabama, Tuscaloosa, Alabama \\ KATHLEEN SHERMAN-MORRIS \\ Department of Geosciences \\ Mississippi State University, Mississippi State, Mississippi \\ JENNIFER SAARI \\ National Weather Service \\ Huntsville, Alabama \\ KIMBERLY BROTHERS \\ Department of Geography \\ University of Alabama, Tuscaloosa, Alabama
}

(Manuscript received 26 June 2020; review completed 20 February 2021)

\begin{abstract}
Although specialized personal and residential Deaf warning technologies exist, receipt and comprehension of tornado warning information from local television is often delayed or misunderstood because of closedcaptioning deficiencies. In order to suggest improvements for the communication of tornado warnings to Deaf and Hard of Hearing $(\mathrm{D} / \mathrm{HoH})$ audiences, interviews and a focus group were conducted within the active tornado counties of Alabama. $\mathrm{D} / \mathrm{HoH}$ individuals generally use more information sources than the hearing population to better understand their risk. Protective action decision-making by our sample was characterized by more hesitation, uncertainty, and indecision than in the hearing population. The most common suggestion for improving tornado-warning communication was to have an American Sign Language (ASL) interpreter shown on screen with a local television meteorologist during a tornado warning. A split-screen television product with an ASL interpreter in a remote studio was prototyped showing that this type of live broadcast is possible for local tornado-warning coverage. Several screen formats were evaluated by a focus group with the conclusion that the ASL interpreter should be on the left side of the screen without obscuring any part of the weather broadcast. The split-screen product with an ASL interpreter resulted in full access to all broadcast information, the ability to make immediate safety decisions, and was welcomed with excitement by the focus-group participants. This modification, along with the education and preparedness efforts of the National Weather Service, help remedy the information gaps and comprehension delays of this underserved population.
\end{abstract}

\section{Introduction}

The southeastern United States receives the greatest variety of severe weather events in the nation throughout the year, and tornado activity is increasing in this region (Gensini and Brooks 2018, Moore and DeBoer 2019). In particular, the possibility of strong and violent tornadoes threatens the southeastern states primarily between November and April, associated with baroclinicity, frontogenesis, and mid-latitude cyclone

Corresponding author address: Jason C. Senkbeil, UA Dept. of Geography 513 University Blvd, Tuscaloosa, AL 35487.

E-mail: jcsenkbeil@ua.edu 
tracks in the transitional and cooler season months. The threat during the shorter daylight months translates into a greater probability of nocturnal tornado events. Thiscoupled with population density, thick forest cover, and a high percentage of residents in mobile homes-has resulted in a greater proportion of injuries and fatalities in this region (Liu et al. 2019, Strader et al. 2019).

The highest tornado risk zone and longest tornado path length zone in the nation for EF2 and greater tornadoes (Coleman and Dixon 2014) cut across a large swath of Mississippi and Alabama. This vulnerability across Mississippi and Alabama is exacerbated further for populations where effective communication of weather information requires modifications in order to reach that target audience. For example, people who have low-vision or blindness (Sherman-Morris et al. 2020) or people with hearing loss or who are part of the Deaf community may require additional channels (e.g., use of sign-language interpreters) for effectively accessing risk information during severe weather. The state of Alabama represents an important location for improvements in emergency communication with a substantial Deaf and hard-of-hearing $(\mathrm{D} / \mathrm{HoH})$ population residing within and adjacent to the high-risk tornado zone. This establishes a critical need to improve tornado-warning communication for $\mathrm{D} / \mathrm{HoH}$ audiences in this region specifically, but the needs for those who are $\mathrm{D} / \mathrm{HoH}$ across the nation justify improvements in how risk communication and information sharing occur during disasters.

Though weather-radio products (such as strobe lights and/or bed vibration attachments) are available to increase access for people with communication disabilities, these accessories are costly. Even with the addition of these accessibility features, improvement still is needed in current communication strategies that provide increased access during disasters (Engelman et al. 2013). For people who are blind, research has established that increased verbal descriptions of geographic information provide more access for this population (Sherman-Morris et al. 2020). Despite the technologies available and even when television closed captioning is provided, $\mathrm{D} / \mathrm{HoH}$ people operate at a significant disadvantage compared to the hearing population in the timely receipt of warning information. This is more prominent during nocturnal events. Once $\mathrm{D} / \mathrm{HoH}$ people become aware of a tornado warning, they often turn to local, wall-to-wall television coverage to see the tornado polygon and arrival times of a tornado in each community. Unfortunately, the closed-captioning text (if available) is often delayed by $3-15 \mathrm{~s}$ from the verbal weather broadcast, and the translation is often out of sync with the information on screen. This causes frustration and confusion among D/ $\mathrm{HoH}$ viewers, and even a 2-s delay in captioning lag can cause confusion (Burnham et al. 1998). Clearly there is demand and need for improvement in the tornadowarning communication process for $\mathrm{D} / \mathrm{HoH}$ audiences. There is no previously published research directly related to the topic of tornado emergency communication in the $\mathrm{D} / \mathrm{HoH}$ population, but several studies have focused on improving emergency preparedness, communication, and response for $\mathrm{D} / \mathrm{HoH}$ people more broadly. Emergency-preparedness training specific to $\mathrm{D} / \mathrm{HoH}$ audiences is rare (Engelman et al. 2013), but culturalcompetence training for law enforcement and first responders has seen increasing popularity (Engelman and Deardorff 2015). In Australia and New Zealand in 2011, sign-language interpreters were first used on television, eliciting a strong positive response from Deaf viewers (McKee 2014). Similarly, in the past four years, American Sign Language (ASL) interpreters have been used sparingly during emergency hurricane broadcasts and with the Federal Emergency Management Agency (FEMA) during disasters. Despite these improvements, only $31 \%$ of state and territorial emergency operation plans specifically mentioned $\mathrm{D} / \mathrm{HoH}$ capabilities (Ivey et al. 2014). A study on availability and readability of emergency-preparedness materials for $\mathrm{D} / \mathrm{HoH}$ audiences suggested greater accessibility of materials in ASL and integration of $\mathrm{D} / \mathrm{HoH}$ people in the design of content (Neuhauser et al. 2013). Text-to-911 services for D/ $\mathrm{HoH}$ audiences also have been increasing in popularity since 2015 (Ellcessor 2019). In a post-disaster setting, a specific Facebook page geared towards a Deaf audience experienced high usage and widespread popularity after an earthquake in Italy (Rotondi et al. 2018). The popularity of social media after a tornado (Stokes and Senkbeil 2016) should be an area of emphasis to assist the $\mathrm{D} / \mathrm{HoH}$ population with the possibility of a dedicated site or social-media feed for $\mathrm{D} / \mathrm{HoH}$ people who are affected by tornadoes.

This research used semi-structured, individual interviews followed by a focus group that identified topical themes organized into four primary research questions:

- Research Question 1 (RQ1): What information sources do D/HoH audiences use and how well is the information understood? 
- Research Question 2 (RQ2): What factors influence tornado-risk perception for $\mathrm{D} / \mathrm{HoH}$ audiences?

- Research Question 3 (RQ3): What are the protective action decisions made by $\mathrm{D} / \mathrm{HoH}$ audiences?

- ResearchQuestion4(RQ4): What modifications could be implemented to make warnings better in both television and operational meteorology?

\section{Background}

Although it is difficult to establish accurate numbers for the incidence of hearing loss in the United States, it is estimated that 30 million people have hearing loss that impairs communication in daily life (Lin 2011). Approximately 11 million people consider themselves to be deaf or to have substantial hearing loss (Walter and Dirmyer 2012). Although people who are $\mathrm{D} / \mathrm{HoH}$ live in both urban and rural locations, there are several locations (e.g. Rochester, NY; Washington D.C.; Austin, TX) that have high incidences of $\mathrm{D} / \mathrm{HoH}$ adult populations and schools, as well as resources and interpreter services that are more readily available to those from the Deaf community. Alabama is not disproportionate compared to other states in its population of $\mathrm{D} / \mathrm{HoH}$ citizens (MMWR 2017), and there is a large state educational school for $\mathrm{D} / \mathrm{HoH}$ students in Talladega, AL. Talladega is also on the edge of the high-risk tornado zone previously mentioned (Fig. 1).

\section{a. Deaf communities}

As with any discussion of culture and communities, it is first important to note that intersectionality (see Crenshaw 2017) and diversity within and across cultural groups are both realistic and essential concepts to understand; that no one person or member of a group can adequately and accurately represent an entire group of people. Accordingly, Deaf communities are diverse in their linguistic, ethnic, and lived identities (e.g., see Smith-Warshaw and Crume 2020). However, people who are culturally Deaf (denoted by the capitalization) in the United States have their own language (ASL) and possess many shared social historical elements (e.g., Deaf schools, Deaf social clubs, Deaf sports) that continue to create cohesion in those with these lived experiences. Although a thorough review of Deaf culture and Deaf communities is not possible here, there are many resources available that explore the historical

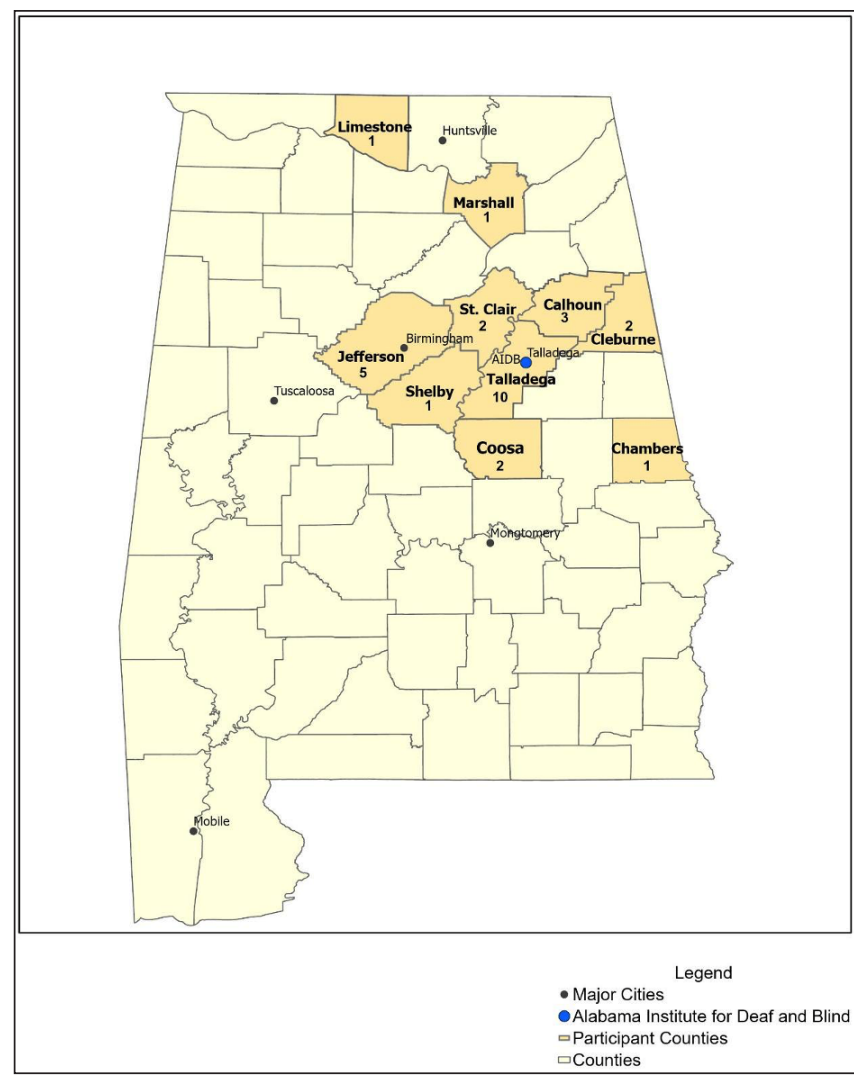

Figure 1. Map of participant counties and major cities in AL. Numbers in each county refer to the number of participants. Click image for an external version; this applies to all figures hereafter.

(Murray, 2019), linguistic (Emmorey et al. 2020), educational (Griffin 2018), cognitive (Marschark and Knoors 2020), visual-spatial (Secora and Emmorey 2019), and diverse social experiences of Deaf communities (Leigh et al. 2020), including a scholarly journal devoted entirely to the topic of Deaf people (i.e., Journal of Deaf Studies and Deaf Education).

One important element of Deaf communities is their focus on the importance of visual information and the visual sensory channel. Whereas it is common for a non-deaf person unaware of Deaf culture to focus on and consider the auditory channel (the ear) and "hearing loss" as the prominent theme when considering deafness, Deaf people instead tend to focus their attention and thinking on the sensory channels they use to function in daily life. It is common for hearing persons to respond to thoughts about deafness as a loss, a deficiency, and even with (culturally inappropriate) negatively valanced emotional responses to the notion of deafness based on their own personal experiences related to hearing (e.g., sad that someone does not have 
access to the beauty of music). Deaf persons instead tend to reflect on a visual experience, visual-spatial language, and their own unique ways of experiencing life, language, and communication as a person who is deaf or hard of hearing.

Most cultural groups tend to believe that their uniqueness contributes to society's diversity and that their culture is rich and meaningful; in Deaf communities this concept has been referred to as Deaf gain (Gale 2020). Furthermore, many culturally Deaf people do not see themselves as disabled, but rather they use a lens to view themselves as belonging to a linguistic minority and logically argue for access to interpreters and other resources based on their ethnic and linguistic status (i.e., Deafnicity; Eckert 2010). Though federal laws mandate equal access to information and communication based on the Americans with Disability Act (ADA), clearly this legislation, although essential, is anchored in a "fix" or medical model perspective that holds that persons who are $\mathrm{D} / \mathrm{HoH}$ inherently are faced with a disability. Again, some people in Deaf communities reject medical or legal models to interpret deafness and instead rely on cultural or linguistic perspectives to understand their identities (Leigh 2009).

\section{b. Challenges of tornado-warning communication}

The breadth of visual-spatial information used by $\mathrm{D} /$ $\mathrm{HoH}$ audiences surpasses that of the hearing population because of their unique language and sociocultural experiences (Secora and Emmorey 2019). Tornado warnings are communicated to $\mathrm{D} / \mathrm{HoH}$ audiences through multiple modalities and technologies, in addition to the information sources of the hearing population. These technologies include bed shakers that can connect to phones, vibrating wristbands, weather radios that vibrate a pillow or mattress, white or red strobe lights that are linked to a weather radio, and weather radios that incorporate a text screen to indicate the type of emergency occurring. Many of these are used in conjunction with mobile devices and wireless emergency text alerts first to receive the tornado warning, followed by most $\mathrm{D} / \mathrm{HoH}$ people turning to local television weather coverage, social media, and family and friends. Unfortunately, most live television weather coverage has insufficient closed captioning (Wood and Weisman 2003) that is either missing words, contains typos, or comes with a lag that is not appropriate for the rapid dissemination of information needed during emergencies. Additionally, captioning does not by itself make emergency information fully accessible to $\mathrm{D} / \mathrm{HoH}$ audiences because of the linguistic differences between English and ASL (Bennett et al. 2018).

An important distinction of ASL is that it is grammatically distinct from English, and ASL does not contain a written form. People who are $\mathrm{D} / \mathrm{HoH}$ and whose first language or primary language is ASL may struggle with comprehension when reading English or relying on captioning because of linguistic differences and social disparities of this population. Accordingly, McKee et al. (2015) found that $48 \%$ of their $\mathrm{D} / \mathrm{HoH}$ sample had insufficient health literacy and were $6.9 \%$ more likely than a non-deaf person to have inadequate health literacy. Their findings indicate that relying on visual information and information in ASL can increase literacy and access to important information. Though captioning may provide additional access to some functionally $\mathrm{D} / \mathrm{HoH}$ people, it is likely a viable tool for those who have late onset of deafness and who are proficient in written and spoken English. Providing ASL translations and improved visualizations of weather information will increase literacy and access in this context (McKee 2014).

\section{Data and methods}

\section{a. Interviews}

A 16-question interview script was created and administered to $28 \mathrm{D} / \mathrm{HoH}$ or Deaf-Blind participants in Talladega and Birmingham, Alabama (see Fig. 1). The question format was open-ended, and participants were encouraged to respond at length with minimal redirection with each answer. The average interview time was $40 \mathrm{~min}$, and participants received a \$25 gift card. Interviews were video recorded and then later transcribed. Three of the questions asked about climatological tornado-risk perception (Ellis et al. 2018, Senkbeil et al. 2019), but those concepts are not discussed in this research. Because of the semistructured nature of the interviews, it was common for a participant to answer particular questions when they were providing responses to a different question in the script. When this happened, topical links were drawn between the two questions so that the question order changed to be more natural and conversational; thus, not every participant was asked the questions in the same order. All the interviews were conducted using qualified and certified sign language interpreters. 
Additionally, the second author is fluent in ASL, is culturally Deaf, and was present for all the interviews. The certified sign language interpreter and the second author both occasionally rephrased the question in sign language if the participant was confused. No assistance with answers was provided to participants when answering questions.

Talladega, Alabama, is home to the Alabama Institute for the Deaf and Blind (AIDB) and the largest population of Deaf residents in the state. AIDB serves almost $25000 \mathrm{D} / \mathrm{HoH}$ individuals across the state at its main campuses in Talladega and through outreach at eight regional centers. AIDB screened and recruited participants for our project using emails, word of mouth, and selective referrals. Because their clients range across proficiency levels of ASL, AIDB personnel wanted to ensure that we had a demographic variety of participants with enough ASL fluency and interest in weather to answer questions about tornado warnings. There were no pre-screening questions. Attempts were made to increase the sample size, but there were issues with transportation and availability for many Deaf residents of Talladega. The majority of our participants lived near Talladega but did not live on campus at AIDB; thus, our participants receive their tornado warning information individually or in tandem with their roommates, spouses, or families and make their own independent or small-group protective action decisions. The participants' ASL proficiency varied, and the majority were Deaf with total hearing loss. Five of the participants interviewed identified as Deaf-Blind, and fewer than five were Deaf with some hearing. Five participants were interviewed at the regional center in Birmingham. Our 28-person sample consisted of equal male and female representation with ages ranging from 19 to 75 .

Questions 3, 4a, 4b, 5, and 6were used for the analysis of RQ1 (Table 1). Probing deeper into how information and alerts from television weather broadcasts are used and understood by $\mathrm{D} / \mathrm{HoH}$ and how this compares to the hearing population was a central theme for RQ1. Because local television severe-weather coverage is so prominent in Alabama, questions were asked about radar images to determine if $\mathrm{D} / \mathrm{HoH}$ audiences find those useful.

RQ2 was assessed from responses to questions 1, 2, 10, and 11 (Table 2). The objective for questions 1 and 2 was to gain background knowledge from our D/ $\mathrm{HoH}$ sample about how the warning system operates for them. The difference between a watch and warning has been asked countless times in previous research. Determining if people can locate their county on a map is a recent important research question that spans the tornado watch and warning timeframes. Convective Outlook maps from the Storm Prediction Center (SPC), maps from National Weather Service (NWS) forecast offices, and inset maps used on television weather all use counties in various color shadings to show where tornadoes are likely to occur or are occurring currently under a warning. Therefore, it is essential to be able to identify your home county on a map if the county names are not displayed.

Question 10, "How do you know you are at risk," was asked to understand what kinds of responses participants would mention if the question did not provide specific direction. For example, they may interpret the question as pertaining to a warning or information source, or they may describe some other aspect of warning communication or their response. Question 11 asked if they ever wonder about the intensity of the tornado on the EF scale during a tornado warning. The responses to this question were compared with question 10 to better grasp risk perception.

RQ3 on protective action decision-making was assessed from questions 7, 8, and 9 (Table 3). Questions 7 and 8 asked participants about actions in the home, if they are at work, or in the car. Question 9 specifically asked participants to recall the actions they took during a recent tornado warning. The responses to these questions were compared to results from previous literature in Alabama about protective action decisionmaking to ascertain potential differences between D/ $\mathrm{HoH}$ audiences and the hearing population.

RQ4 was assessed by responses to the last questions of our interviews (Table 4). These questions specifically asked participants to discuss the ways the tornadowarning process could be improved to better serve the $\mathrm{D} / \mathrm{HoH}$ population. These were important, overarching questions that linked several themes, and these were always asked last for every participant even if they partially answered these questions when providing responses to earlier questions.

\section{b. Product development}

The information gathered (especially comments related to closed captioning and the desire for an ASL interpreter) from our interviews was used in the development of a prototype of a media/television weather product that can help improve communicating 
Table 1. Responses to RQ1, "What information sources do D/HoH audiences use and how well is the information understood?" The number of participants who answered each question varied, and participants could provide more than one answer for each question. For question 3, some participants answered "James Spann," a popular broadcast meteorologist in Birmingham, AL.

\begin{tabular}{|c|c|c|c|}
\hline Question \# & Question Description & Question \# & Question Description \\
\hline 3 & $\begin{array}{l}\text { Preferred way of getting } \\
\text { tornado warning } \\
\text { information? }\end{array}$ & 5 & $\begin{array}{l}\text { What are barriers } \\
\text { for receiving tornado } \\
\text { warning information? }\end{array}$ \\
\hline Response Codes & \# Occurrences, Percent & Response Codes & \# Occurrences, Percent \\
\hline TV News & $19,30 \%$ & No internet & $5,17 \%$ \\
\hline Phone apps & $12,19 \%$ & $\begin{array}{l}\text { Inaccessible audible } \\
\text { warnings }\end{array}$ & $5,17 \%$ \\
\hline Phone alert/SMS messages & $9,14 \%$ & No or poor captions & $5,17 \%$ \\
\hline Alarm system & $6,10 \%$ & Power outage & $3,10 \%$ \\
\hline WOM/Friends/Family & $6,10 \%$ & Lack of warning devices & $3,10 \%$ \\
\hline James Spann & $4,6 \%$ & Social connections cutoff & $3,10 \%$ \\
\hline Emails & $2,3 \%$ & $\begin{array}{l}\text { Poor phone GPS/ } \\
\text { misinformation }\end{array}$ & $2,7 \%$ \\
\hline $\begin{array}{l}\text { Internet search (e.g., weather. } \\
\text { com) }\end{array}$ & $2,3 \%$ & Night weather occurrences & $1,3 \%$ \\
\hline $\begin{array}{l}\text { National Weather Service } \\
\text { (NWS) }\end{array}$ & $2,3 \%$ & Lack transportation & $1,3 \%$ \\
\hline Social media & $1,2 \%$ & Limited battery life & $1,3 \%$ \\
\hline & & Information overload/jargon & $1,3 \%$ \\
\hline Question \# & Question Description & Question \# & Question Description \\
\hline $4 \mathbf{a}$ & $\begin{array}{l}\text { Do the TV forecasters' } \\
\text { descriptions of the } \\
\text { radar contribute to your } \\
\text { understanding of your } \\
\text { safety? }\end{array}$ & 6 & $\begin{array}{l}\text { Is tornado weather } \\
\text { information easy or } \\
\text { difficult to understand? }\end{array}$ \\
\hline Response Codes & \# Occurrences, Percent & Response Codes & \# Occurrences, Percent \\
\hline Yes & $13,68 \%$ & Easy & $13,54 \%$ \\
\hline If there are captions & $4,21 \%$ & Difficult (e.g., weird) & $7,29 \%$ \\
\hline No & $2,11 \%$ & Depends on captions & $3,13 \%$ \\
\hline & & Unsure & $1,4 \%$ \\
\hline Question \# & Question Description & & \\
\hline $4 b$ & $\begin{array}{l}\text { How do the descriptions } \\
\text { help? }\end{array}$ & & \\
\hline Response Codes & \# Occurrences, Percent & & \\
\hline $\begin{array}{l}\text { Provides directionality/ } \\
\text { location }\end{array}$ & $5,36 \%$ & & \\
\hline Repetition & $3,21 \%$ & & \\
\hline Visualizations & $3,21 \%$ & & \\
\hline Elaborations & $2,14 \%$ & & \\
\hline Feel more secure & $1,7 \%$ & & \\
\hline
\end{tabular}


Table 2. Responses to RQ2 "What factors influence tornado risk perception for D/HoH audiences?" The number of participants who answered each question varied, and participants could provide more than one answer for each question.

\begin{tabular}{|c|c|c|c|}
\hline Question \# & Question Description & Question \# & Question Description \\
\hline 1 & $\begin{array}{l}\text { Know difference be- } \\
\text { tween a tornado watch } \\
\text { and warning? }\end{array}$ & 10 & $\begin{array}{l}\text { How do you know you're } \\
\text { at risk? }\end{array}$ \\
\hline Response Codes & \# Occurrences, Percent & Response Codes & \# Occurrences, Percent \\
\hline Yes & $19,68 \%$ & Weatherman/TV & $11,33 \%$ \\
\hline No & $9,32 \%$ & Internet/apps & $8,24 \%$ \\
\hline & & Feel in air (sense it), aching & $4,12 \%$ \\
\hline Question \# & Question Description & Sky and cloud changes & $3,9 \%$ \\
\hline 2 & $\begin{array}{l}\text { Can you pick out your } \\
\text { county on a map? }\end{array}$ & A warning & $3,9 \%$ \\
\hline Response Codes & \# Occurrences, Percent & Neighbors tell me & $3,9 \%$ \\
\hline Yes & $14,64 \%$ & Pet acts different & $1,3 \%$ \\
\hline No & $4,18 \%$ & Question \# & Question Description \\
\hline Unsure & $4,18 \%$ & 11 & $\begin{array}{l}\text { Do you ever wonder if } \\
\text { it is an average or really } \\
\text { bad tornado? }\end{array}$ \\
\hline & & Response Codes & \# Occurrences, Percent \\
\hline & & Yes & $10,50 \%$ \\
\hline & & A tornado is a tornado & $8,40 \%$ \\
\hline
\end{tabular}

information to $\mathrm{D} / \mathrm{HoH}$ audiences during a tornado event. We developed a novel design prototype for information communication technology (ICT) to address the shortcomings in accessibility of current emergency weather warnings for the $\mathrm{D} / \mathrm{HoH}$ who rely on ASL. This technology will allow ASL interpreters to remotely create ASL interpreting for localized emergency weather forecasts in real time. Recent research has examined how remote voice-interpreting initiatives for health or emergency information are being evaluated for best practices (Havelka 2020), but little research exists on the use of remote ASL interpreting. The development and testing for this system was a two-part process:

1. We first built, designed, and tested a remotebased system for providing real-time ASL interpreting for emergency weather via media studio technologies and equipment, and
2. We then provided several versions of the ASLtranslated video feeds of emergency weather forecasts to $\mathrm{D} / \mathrm{HoH}$ consumers in a focus group to gauge ways these tools may increase accessibility of emergency weather information.

Although Telecommunications Relay Services (TRS) already exist for the $\mathrm{D} / \mathrm{HoH}$ (also known as Video Relay Services or Video Interpreting Services), these technologies rely only on ASL interpreters to connect $\mathrm{D} / \mathrm{HoH}$ telecommunications consumers with those who are hearing via telephone or videophone correspondence. These tools are not yet established for mass communication or reaching audiences during emergencies.

Approximately ten Internet-based TRS providers are based on the Federal Communications Commission's website, and these services are supported by federal funds under the Title IV of the ADA (Section $255)$ and the ADA of 1990. These infrastructures are well-established, which allows them to be adapted and utilized to build an additional ICT for spreading 
Table 3. Responses to RQ3, "What are the protective action decisions made by D/HoH audiences?" The number of participants who answered each question varied, and participants could provide more than one answer for each question.

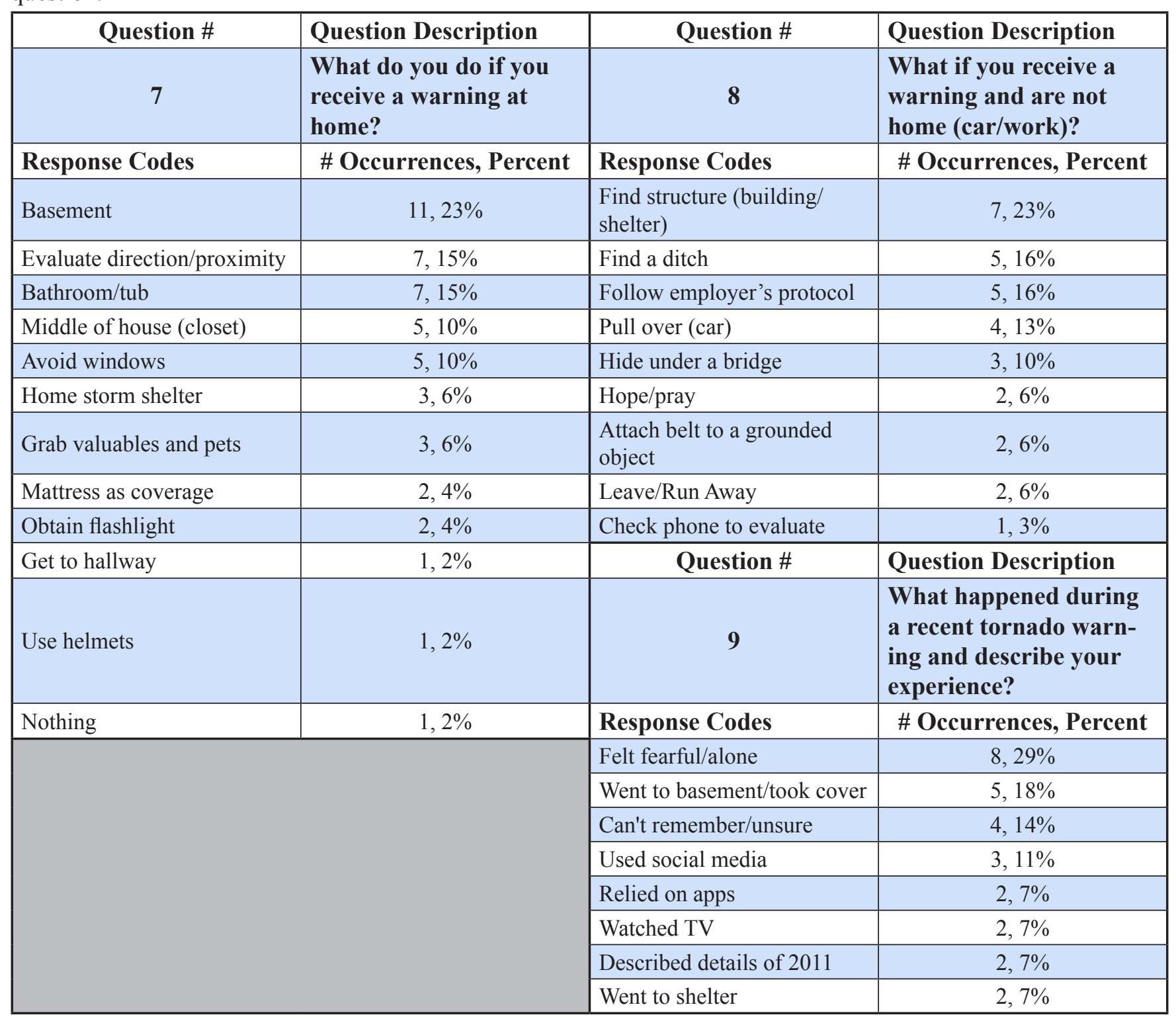

risk information to vulnerable populations in remote locations during emergency weather.

To alleviate the time, travel, and risk constraints caused by onsite interpreting during a media broadcast of emergency weather, we designed and developed a pilot of an ASL emergency weather broadcast using a recorded past tornado event from Tuscaloosa, Alabama. The goal in developing this prototype is to build new tools for existing offsite call centers (already being used by TRS companies) that could be utilized to offer professional and trained ASL interpreters for remote locations across the southeastern United States in real time during emergency weather. Using high speed Internet and video streaming technology, it would be feasible for Deaf/HoH citizens across the United States to access local emergency weather information by requesting that their local weather forecast be ASLinterpreted in real time. Some local interpreters have done this on their own using social media technologies such as FaceTime or Facebook Live and interpreted what they are hearing on the radio to Deaf audiences who follow them on social media.

Our method of building this ASL emergency weather interpreting tool was in partnership with a 
Table 4. Responses to RQ4, "What modifications could be implemented to make warnings better in both television and operational meteorology?" The number of participants who answered each question varied, and participants could provide more than one answer for each question.

\begin{tabular}{|c|c|c|c|}
\hline Question \# & Question Description & Question \# & Question Description \\
\hline 15 & $\begin{array}{l}\text { How could the tornado } \\
\text { warning process improve } \\
\text { to better alert you? }\end{array}$ & 16 & $\begin{array}{l}\text { What do you want } \\
\text { meteorologists/NWS to } \\
\text { know about deaf people } \\
\text { to improve } \\
\text { communication? }\end{array}$ \\
\hline Response Codes & \# Occurrences, Percent & Response Codes & \# Occurrences, Percent \\
\hline Text alerts (e.g., EMA alert) & $6,24 \%$ & Have an interpreter & $12,26 \%$ \\
\hline $\begin{array}{l}\text { More warning systems } \\
\text { (e.g.. Sirens, flashing lights) }\end{array}$ & $5,20 \%$ & Phone alerts work best & $8,17 \%$ \\
\hline Weather warning devices & $3,12 \%$ & Improve captions & $8,17 \%$ \\
\hline Captions & $2,8 \%$ & Weather radio test alerts & $4,9 \%$ \\
\hline Nothing & $2,8 \%$ & Visualizations on TV & $3,7 \%$ \\
\hline Use of vibration in warnings & $2,8 \%$ & Educational opportunities & $3,7 \%$ \\
\hline Visual system & $2,8 \%$ & Braille & $3,7 \%$ \\
\hline Inclusion of braille & $1,4 \%$ & $\begin{array}{l}\text { Localize warnings more } \\
\text { (offer zip codes when giving } \\
\text { warnings) }\end{array}$ & $3,7 \%$ \\
\hline $\begin{array}{l}\text { Increase cell phone signal } \\
\text { strength }\end{array}$ & $1,4 \%$ & TV alerts & $1,2 \%$ \\
\hline $\begin{array}{l}\text { Tools independent } \\
\text { of power grid }\end{array}$ & $1,4 \%$ & Email warnings & $1,2 \%$ \\
\hline
\end{tabular}

public professional digital media center. Our team was assisted by the media professionals employed by the studio, and we partnered with two professional ASL interpreters who work with FEMA during disasters. The ASL-interpreting team traveled from Washington, DC, where they are based and spent a full day with our team developing the prototype that was used for the focus group. One of the interpreters works-full time for FEMA and is a Certified Deaf Interpreter (CDI), and the partner is a hearing contract interpreter who works closely with the FEMA team to provide accessible ASL interpreting during disasters. Though it is not common knowledge, many of the sign language interpreters who are seen on television during local government press releases are Deaf themselves. They are relying on the signing of their hearing counterpart who is seated (or standing) in the audience interpreting, word for word, the spoken message into signed vocabulary. The job of the CDI is to then develop a universally accessible, grammatically correct ASL version of the messaging for $\mathrm{D} / \mathrm{HoH}$ audiences (Fig. 2).
During the COVID-19 pandemic, many states provided live emergency government press releases that utilized CDIs and tools similar to the one we developed for this study. There are several constraints in providing

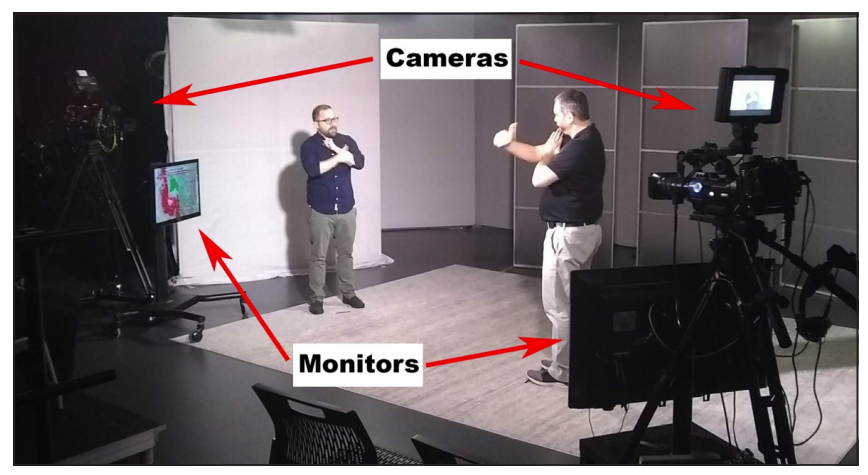

Figure 2. A hearing ASL interpreter (left) works with a CDI in the studio creating live-streaming interpreting for emergency weather broadcasts. (Note: Two cameras were used for research purposes to capture the hearing interpreter's signs, but only one camera facing the CDI is necessary for broadcasting during actual weather broadcasts.) 
Table 5. Summary of results and recommendations.

\begin{tabular}{|c|c|}
\hline Research Question & Research Question \\
\hline $\begin{array}{l}\text { RQ1: What information sources do } \mathrm{D} / \mathrm{HoH} \text { people use, and } \\
\text { how well is the information understood? }\end{array}$ & $\begin{array}{l}\text { RQ2: What factors influence tornado risk perception for D/ } \\
\text { HoH people? }\end{array}$ \\
\hline Results & Results \\
\hline $\begin{array}{l}\text { 1. Variety of sources used, similar to hearing population } \\
\text { 2. TV used less often than hearing population (captioning } \\
\text { problems) } \\
\text { 3. Technology (e.g., specialized weather radio, strobe lights, } \\
\text { bed shakers) } \\
\text { 4. Information is generally understood } \\
\text { 5. Decision-making delay due to processing inaudible infor- } \\
\text { mation }\end{array}$ & $\begin{array}{l}\text { 1. No major differences between our } \mathrm{D} / \mathrm{HoH} \text { sample and } \\
\text { hearing population } \\
\text { 2. Some evidence suggests greater sensory perception of } \\
\text { environmental severe weather cues with our } \mathrm{D} / \mathrm{HoH} \text { sample }\end{array}$ \\
\hline Recommendations & Recommendations \\
\hline $\begin{array}{l}\text { The meteorological community should continue to work } \\
\text { with partners to enhance existing technology and consider } \\
\text { new ideas to reduce decision-making delay times. }\end{array}$ & $\begin{array}{l}\text { Local NWS field offices should continue working to better } \\
\text { educate D/HoH people about SPC Convective Outlooks, } \\
\text { risk categories, tornado watches, and tornado warnings so } \\
\text { that D/HoH people will better understand their risk. }\end{array}$ \\
\hline Research Question & Research Question \\
\hline $\begin{array}{l}\text { RQ3: What are the protective action decisions made by D/ } \\
\text { HoH people? }\end{array}$ & $\begin{array}{l}\text { RQ4: What modifications could be implemented to make } \\
\text { warnings better in both television and operational meteorol- } \\
\text { ogy? }\end{array}$ \\
\hline Results & Results \\
\hline $\begin{array}{l}\text { 1. No differences between our } \mathrm{D} / \mathrm{HoH} \text { sample and hearing } \\
\text { population } \\
\text { 2. Evidence suggests every tornado warning perceived as } \\
\text { same level of risk }\end{array}$ & $\begin{array}{l}\text { 1. D/HoH people enthusiastically support and need a } \\
\text { dedicated television broadcast with a split-screen format } \\
\text { featuring an ASL interpreter during wall-to-wall tornado } \\
\text { warning coverage. } \\
\text { 2. The NWS continues to develop outreach and educational } \\
\text { programs to better serve the D/HoH community. }\end{array}$ \\
\hline Recommendations & Recommendations \\
\hline $\begin{array}{l}\text { Local NWS field offices should continue working to better } \\
\text { educate D/HoH people about SPC Convective Outlooks, } \\
\text { risk categories, tornado watches, and tornado warnings so } \\
\text { that D/HoH people will better understand their risk. }\end{array}$ & $\begin{array}{l}\text { 1. Television stations should begin to evaluate feasibility of } \\
\text { obtaining technology to broadcast a separate D/HoH feed } \\
\text { with a split-screen, ASL-interpreter format. } \\
\text { 2. Local NWS field offices should continue their education } \\
\text { and outreach efforts and build relationships with state and } \\
\text { local Deaf agencies. }\end{array}$ \\
\hline
\end{tabular}

real-time, CDI-interpreted events during emergencies, such as increased costs, licensing, and legal permissions associated with regulatory agencies that govern copyrighted material that may need to be replicated or re-broadcast. During the 2020 presidential debates, the non-profit organization d-pan.org provided real-time, live ASL interpreting on their website, showing it is possible to provide real-time ASL interpreting.

\section{c. Focus group}

Versions of the ASL-interpreted products were then shared with and evaluated by a seven-member focus group (three males and four females) of Deaf participants from the Tuscaloosa area. These participants were recruited by the regional AIDB center in Tuscaloosa, and they did not participate in the interviews. A separate focus group was chosen because we did not want to introduce bias by using interview participants who we had already engaged in conversation about 
the possibility of having an ASL interpreter on screen. Some of the interview participants asked us questions about that possibility or had strong opinions, and we thought those individuals would potentially dominate a focus group. The Tuscaloosa focus group was told that they would be evaluating new weather technology for $\mathrm{D} / \mathrm{HoH}$ people, but they did not have prior knowledge of our plans. Of particular interest were two questions:

1. Was there a clear preference among screen layout and design formats that most effectively communicated the information?

2. Did any of the designs improve risk perception by causing participants to indicate they would take protective action faster?

\section{Analysis and discussion}

a. RQ1: What information sources do $\mathrm{D} / \mathrm{HoH}$ audiences use, and how well is the information understood?

The $\mathrm{D} / \mathrm{HoH}$ sample from our research was not considerably different from the hearing population in how they access tornado-warning information. Like the hearing population, the $\mathrm{D} / \mathrm{HoH}$ participants in our sample primarily used local television weather in conjunction with one or more other sources, including phone apps or phone alerts, bed shakers, or strobe lights (see Table 1). These findings closely match results of previously published research from the hearing population (Luo et al. 2015, Stokes and Senkbeil 2016, Walters et al. 2019). However, there are a few notable differences. The most common fear of respondents in our sample was sleeping through a tornado warning at night, resulting in the majority of our respondents sleeping with their mobile phones set to vibrate under their pillows. The poor quality of closed captioning on local television weather was a common complaint, and this translates into a lower percentage of $\mathrm{D} / \mathrm{HoH}$ people exclusively relying on local television weather (or not using it at all) compared to the hearing population. The closed-captioning text is frequently delayed from what the meteorologist is saying, but more importantly, the words in the text often do not match what the meteorologist said or contain typos that distort the fidelity of the message. This causes $\mathrm{D} / \mathrm{HoH}$ people to supplement local television weather coverage with information from other sources to fill in the gaps.
The answers to question 6 (see Table 1) suggest that a slight majority of D/HoH audiences understood tornadowarning information. Because the most common source of information is local television weather, questions $4 \mathrm{a}$ and $4 \mathrm{~b}$ asked for greater elaboration on the usefulness of radar images and what aspects of local television weather help them understand their risk. Radar images of tornadoes during live, wall-to-wall coverage are helpful (68\%), but they are more helpful if the closedcaptioning text is accurate and in sync with the image (21\%). Specifically, radar images were noted for providing directionality and location of the tornado $(36 \%)$, and repetition of the information was important $(21 \%)$ as $\mathrm{D} / \mathrm{HoH}$ audiences are frequently operating on an information receipt-time deficit.

\section{b. RQ2: What factors influence tornado risk perception for D/HoH audiences?}

The percentage of our sample who understood the difference between a tornado watch and tornado warning $(68 \%)$ was lower than results from previously published research (Schultz et al. 2010, Sherman-Morris 2010, Balluz et al. 2000). One possible explanation for the higher percentage in our sample who did not understand this difference is their protective-action decisionmaking experiences. As indicated in our interviews, a greater number of $\mathrm{D} / \mathrm{HoH}$ people make safety decisions assisted by others compared to non-deaf populations. These safety and planning decisions for $\mathrm{D} / \mathrm{HoH}$ persons often happen in consultation with family members such as their hearing children (Singleton and Tittle 2000). Assistance from others is even more relevant in the context of safety preparations for people who are DeafBlind because many work closely with support service providers who assist them in their daily functions (Bourquin et al. 2006). Another possible explanation is that a lower percentage of $\mathrm{D} / \mathrm{HoH}$ people use television for their warning information, which would create less exposure to terminology and more unfamiliarity. The percentage of our sample who could identify their county on a map was similar to the watch versus warning result (64\%). Taken together, these results confirm that $33 \%$ of our sample was operating at an information disadvantage before a tornado warning is issued (see Table 2). This is a concern if the true population value is within 10 percentage points on either side of this result.

When asked how they know they are at risk, 67\% of participants answered with some type of information source or warning notification. Of the remaining 33\%, 
$9 \%$ stated they communicate with neighbors, and $24 \%$ used a combination of feelings, senses, or visual cues from the changing weather conditions or pet behavior (see Table 2). It is uncertain how this percentage compares to the hearing population without conducting a separate study. However, the increased attention to visual sensory details among $\mathrm{D} / \mathrm{HoH}$ people in daily life is believed to also apply to increased visual sensory perception of changing environmental and weather conditions (Pavani and Bottari 2012, Codina et al. 2017). Half of the participants wondered about tornado intensity when under a tornado warning. Participants were asked about their knowledge of SPC convective outlook categories as a follow-up question. Only two of the participants had ever heard of the SPC or were aware of the convective outlook categories. This provided an opportunity for the authors to explain what a high- and moderate-risk outlook means and to refer participants to the SPC website for potential outbreaks in the future.

\section{c. RQ3: What are the protective action decisions made by $\mathrm{D} / \mathrm{HoH}$ audiences?}

Questions 7, 8, and 9 were used for the analysis of RQ3 (see Table 3). Like RQ1, the responses for protective action decision-making in our $\mathrm{D} / \mathrm{HoH}$ sample closely matched those of the hearing population (Senkbeil et al. 2012). The most common response to question 7 was to go to the basement, followed by bathroom or bathtub, and middle of the house or closet. One notable distinction was the number of participants commenting about evaluating the direction and proximity of the tornado. Many people may check for visual confirmation as a way of assessing the urgency of their risk (Walters et al. 2020), and similarly, some of our $\mathrm{D} / \mathrm{HoH}$ sample $(15 \%)$ reflected on evaluating the direction and proximity as an early response to a warning.

Results from previous research have largely ignored scenarios involving tornado warnings at work or in a car. The responses to question 8 followed the recommended shelter strategy if in a car to find a sturdy building or use a ditch as a last resort. It is concerning that five participants mentioned hiding under a bridge or attaching a belt to an object. Several safety campaigns have stressed the dangers of seeking shelter under a bridge and using a belt as seen in the movie Twister. These responses suggest that more work is needed to educate the public on how to best respond to a tornado if someone is in a car.
The actions taken during their last tornado warning offer a glimpse into how many people followed the actions they described in question 9. The most popular response was to feel fearful and alone. It is unknown how many participants felt this way and took shelter, or how many felt this way and were unable to act. An equal number of participants remarked about some aspect of continuing to seek information instead of seeking shelter. Although going to a basement was the most common response in question 7 , only five participants actually used that shelter strategy during their last tornado warning. It is unknown how many participants had a basement available during their last tornado warning, or if some participants interpreted question 7 to mean what they should do during a tornado warning. Another six participants could not remember what they did or described the details of the 27 April 2011 tornado outbreak without a relevant response to the question. The broad variety of responses to this question paints a picture of uncertainty and inaction during the latest tornado warning for the majority of our participants. This possible state of inaction is exactly why this research is such an important breakthrough for the $\mathrm{D} /$ $\mathrm{HoH}$ population.

d. RQ4: What modifications could be implemented to make tornado warning information better for both television and operational meteorology?

\section{1) BROADCAST METEOROLOGY PRODUCT WITH ASL INTERPRETER ON SCREEN}

Following the advice of our interview participants, a split-screen television meteorology product was created with an ASL interpreter on screen next to the broadcast meteorologist. This was the most popular answer from interview participants $(26 \%)$, in addition to improvements in existing technologies (see Table 4). As seen above in RQ3, the interpretation of the wording of the question could have contributed to confusion on the differences between answers to questions 15 and 16 (Table 4). For example, participants may have interpreted question 16 to mean what could be done to improve available technology instead of what new ideas would represent an improvement. In our exit conversations, we asked participants about their preferences of having an interpreter on screen if they did not provide that answer. All participants who watch television tornado warning coverage were supportive of the suggestion of an ASL interpreter on screen. 
A variety of product designs were considered, and three were produced based on the professional guidance of broadcasters and specialists in the media center. These were then evaluated by a focus group of seven $\mathrm{D} /$ $\mathrm{HoH}$ participants over a 3-h period. As stated in section 3 , the goals were to determine a clear preference among screen layout and design formats and to see if any of the designs caused participants to indicate they would take protective action faster.

The focus group watched several 2-min segments for each product design of archived tornado warning coverage from meteorologist Richard Scott at WVUA in Tuscaloosa. Discussions were held after each segment. As described in the methods, the interpreter team shown in the split screen (see Fig. 2) translated the archived tornado-warning coverage as if they were seeing it live. They were recorded as they interpreted the footage in real time, and they were not shown the footage in advance. They were not allowed to stop, edit, or redo any of their interpreting during or after the simulation. During our trials, the interpreters commented on the amount of meteorological jargon and the difficulties of rapidly translating this into ASL. Because of the high cognitive load, it is suggested that either an experienced CDI and hearing interpreter team should be used, or 2-3 individual ASL interpreters should be available to work in 15-45 min shifts before seamlessly rotating off screen, depending on how active or busy the tornado outbreak is.

Design formats consisted of two side-by-side designs and a corner inset design (Fig. 3). All of the focus group participants showed excitement upon seeing the products at the start of the first clip. The corner inset design (Fig. 3a) was universally disliked by all seven members of the focus group. Within seconds of those segments playing, focus group members began to complain in ASL about some of the screen being obscured. Indeed, the radar options menu was obscured, and even though this was extraneous information, the focus group participants did not know this. If the goal is to make the warning process clearer for Deaf $/ \mathrm{HoH}$ audiences, there cannot be any confusion or doubt when part of the screen is obscured. From their perspective, missing information may be relevant or important. Equal access to information is also a civil right protected by ADA laws.

Both side-by-side designs (Fig. 3b and 3c) caused lengthy discussion and debate among the focus group participants. The focus group considered the larger design ( $3 b$ ) to be the best of our options, but the group
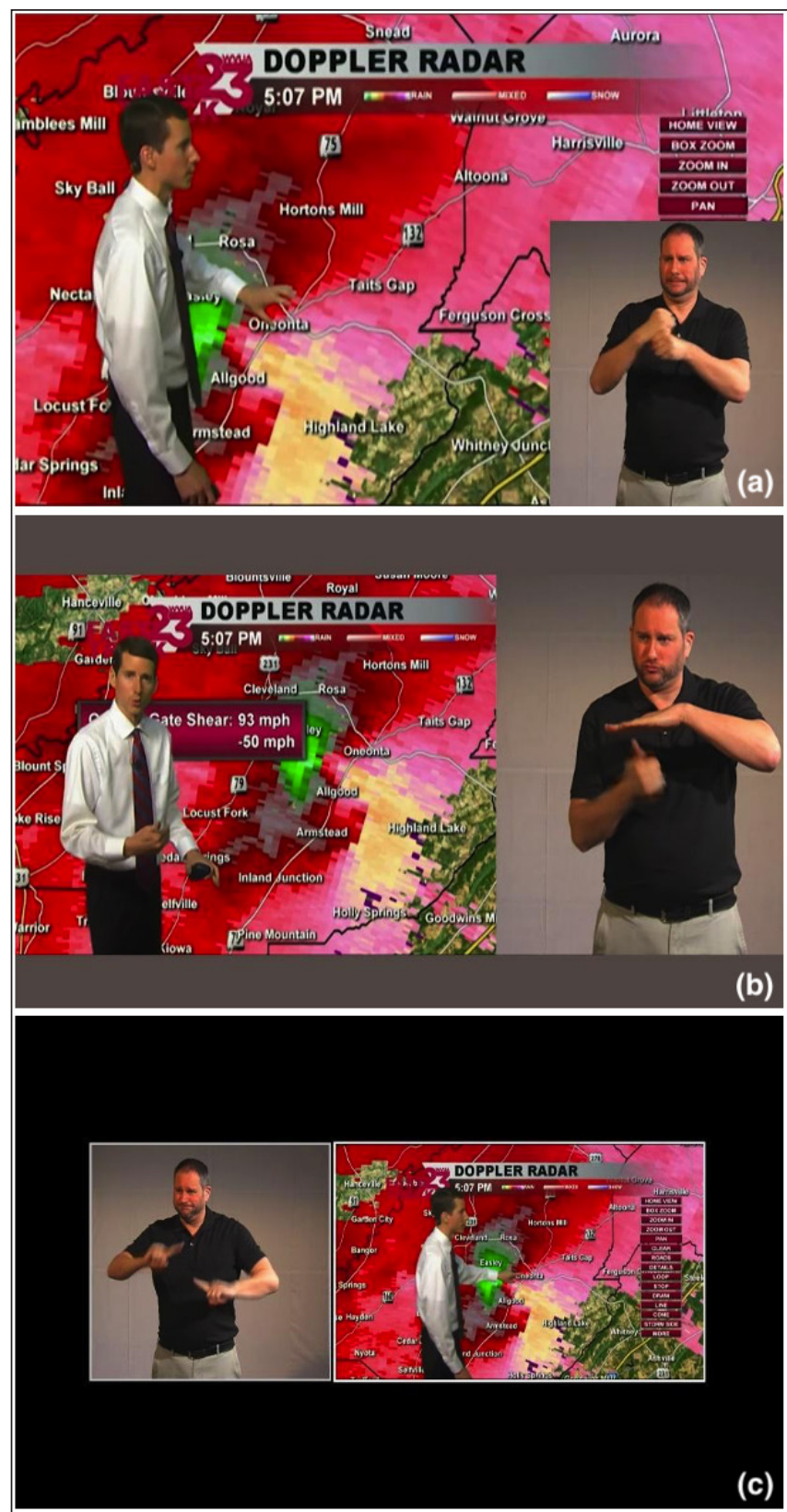

Figure 3. Screen layout and design formats evaluated by our focus group: (a) corner inset, (b) side-by-side, right large, and (c) side-by-side, black small. The best design for $\mathrm{D} / \mathrm{HoH}$ audiences is a side-by-side design [similar to (b)], but with the interpreter on the left and as large as possible. Footage provided by WVUA with chief meteorologist Richard Scott.

did not want the ASL interpreter to be located on the right side of the screen. They recommended that general design but preferred that the ASL interpreter position be changed to show the interpreter on the left side of the screen. Information is read from left to right, so from these observations it is recommended that the 
ASL interpreter be located on the left-hand side to increase accessibility for $\mathrm{D} / \mathrm{HoH}$ users. Background colors, contrast, patterns, and other display formats showed inconsistent results across the group. Overall, the group agreed that unnecessary moving backgrounds and patterns in the background created a distraction. A plain dark background was preferred over other options, which aligns with the suggestions of the Registry of Interpreters for the Deaf.

All the designs were preferred by the focus group against the current status of not having an ASL interpreter on screen, and all designs improved the speed of protective action decision-making compared to the status quo. It was hypothesized that some designs would lead to a stated intent to take protective action faster than other designs, but there were no apparent differences among our options. Our focus group did not think that certain radar images or storm scenarios were more or less dangerous than others. One participant indicated "a tornado warning is a tornado warning," and this sentiment was agreed upon by the rest of the focus group. Similar comments were made in response to question 11 in Table 2, indicating that the response or protective-action behavior in response to all tornado warnings is the same if residents are at home. Perhaps additional future research about protective action decision-making will be more relevant if the technology with an ASL interpreter becomes widely used and D/ $\mathrm{HoH}$ audiences have time to evaluate and compare results from real storm events. Overall, the $\mathrm{D} / \mathrm{HoH}$ participants in the focus group were extremely positive about the future possibility that live ASL interpreting could be available for severe weather information in real time.

\section{2) NWS}

The NWS offers basic meteorology and storm spotter workshops prior to severe weather season. Typically, these workshops are not accessible for all, lacking Communication Access Realtime Translation services and ASL interpreters. However, by building partnerships within the $\mathrm{D} / \mathrm{HoH}$ community, these communication services and more focused materials can be provided, making such classes fully accessible. Some NWS offices have been hosting targeted, fully accessible classes since 2012, and this outreach endeavor has continued to spread to other offices across the country (NOAA 2020c).
Including better suited materials for the workshop may seem like a small change, but it allows for an enhanced and more inclusive learning experience. Combined with specialized communication services, this ensures the material is properly conveyed and understood. Minor adjustments to workshop materials are made in order to better tailor them to the audience. Some changes to the presentation materials include:

1. an expanded basic radar overview so that attendees can better understand what they see on a radar image when there are no captions available, and

2. what else to have in a safety kit such as communication cards, or pen and paper to better communicate with first responders.

Furthermore, attendees at several workshops have been provided with a free weather radio and strobe light attachment or a bed shaker supported by organizational partnerships, donations, and other research contributions. Providing radio equipment with accessible features for $\mathrm{D} / \mathrm{HoH}$ users allows attendees to not only leave the workshop with a better understanding of weather and weather safety, but to own a device that has the potential to save their life in future weather events.

Additional materials also have been developed for use inside and outside of the workshop, including weather safety videos that feature an ASL interpreter and captioning, updated outreach materials, and a National Oceanic and Atmospheric Administration (NOAA) website (NOAA 2020a). An example of these new materials is related to lightning safety. Traditional lightning safety revolves around the slogan, "When Thunder Roars, Go Indoors," which is audible reliant. New lightning safety outreach materials with visual cues in mind were developed between the NWS, D/ $\mathrm{HoH}$ partners, and workshop attendees over the course of four years. During this time, a new slogan, "See a Flash, Dash Inside!" was developed along with a new informational logo and a public service announcement that included ASL and open captions. "See a Flash, Dash Inside!" materials were officially rolled out by NOAA and the NWS in 2016 and run parallel to existing "When Thunder Roars, Go Indoors" materials (NOAA 2020a). Other safety videos developed include topics such as severe thunderstorms, tornadoes, flooding, hurricanes, and rip currents. The NWS Weather Ready 
Nation website hosts all the extra materials so they can be accessed at any time across the country. The combination of fully accessible weather education and safety workshops, additional educational materials, and alerting technology, such as weather radios and attachments, helps this underserved group in our community be prepared for the next hazardous weather event, day or night.

\section{Conclusion}

Interviews were conducted with $\mathrm{D} / \mathrm{HoH}$ participants in Alabama to determine deficiencies in the tornado warning communication process for this population. Four primary research questions were investigated. These questions asked about information sources and comprehension, tornado risk perception factors, protective action decision-making, and modifications for improvement for $\mathrm{D} / \mathrm{HoH}$ audiences. Results and recommendations are summarized in Table 5 and discussed in the following paragraphs.

Similar to the hearing population, the preferred method for receiving tornado-warning information was local television coverage; however, not all participants in our sample relied on television. Closed captioning time delays and errors in providing text-based access during emergencies is a primary challenge, but a larger rooted issue with using captions for $\mathrm{D} / \mathrm{HoH}$ audiences is that reading English via captions requires use of second language comprehension. Research has established that people who are $\mathrm{D} / \mathrm{HoH}$ have lower English reading comprehension levels than non-deaf persons (Bélanger and Rayner 2015), and that reading English requires increased cognitive load and working memory constraints on $\mathrm{D} / \mathrm{HoH}$ as they may have had to learn English through text forms (and not through hearing and speaking the language). Consequently, even in the best situations where captions are not faced with lags or errors, this modality is not adequate for sharing timely information during emergencies with $\mathrm{D} /$ $\mathrm{HoH}$ audiences.

The stated protective action decisions made by our $\mathrm{D} / \mathrm{HoH}$ participants were similar to the hearing population, but the actions taken during their last tornado warning painted a picture of uncertainty and indecision. It was troubling to learn that a number of our participants either continued to search for more information instead of sheltering or felt fearful and alone and unsure about what actions to take.
The most popular suggestion for ways to improve the tornado warning communication process was to have an ASL interpreter live on screen with local television tornado-warning coverage. We designed and developed a pilot of an ASL emergency weather broadcast using recorded tornado warnings with Richard Scott from WVUA in Tuscaloosa. Using high-speed Internet and video-streaming technology with ASL interpreters would make it technologically feasible for $\mathrm{D} / \mathrm{HoH}$ citizens across the United States to access severe weather information by requesting that their local weather forecast be ASL-interpreted in real time. The implementation of these suggested modifications for accessibility by television stations is possible, although financial barriers exist. The authors hope that the results presented from this research will start that discussion.

Our Deaf focus group concluded that a side-by-side format with the ASL interpreter on the left side of the screen with a dark and plain background would be the best design to use. The ASL interpreter cannot obscure any part of the screen or information being shown on the local television weather broadcast. Having an ASL interpreter next to a local television weather forecaster eliminated the confusion and delayed understanding of tornado warning information that $\mathrm{D} / \mathrm{HoH}$ people currently experience. It should be noted that, in addition to the creation of an ASL split-screen product, other popular suggestions were for improvements to existing captioning and phone alerts.

In addition to our suggested improvements for broadcast meteorologists, the NWS is expanding its outreach efforts for the $\mathrm{D} / \mathrm{HoH}$ population through more accessible workshops on basic meteorology and storm spotting. ASL-interpreted weather safety videos, updated outreach materials, and the Weather Ready Nation website are other initiatives that are helping improve preparedness before severe weather events (NOAA 2020c). It is hoped that these new products and efforts will lead to widespread implementation and coordination across the weather enterprise so that the $\mathrm{D} / \mathrm{HoH}$ population will be prepared, receive, and understand timely warning information to take immediate protective action. Furthermore, because only a few members of our $\mathrm{D} / \mathrm{HoH}$ sample had ever heard of the SPC and Convective Outlooks issued by the SPC, it is recommended that the SPC and local NWS field offices coordinate efforts to more broadly disseminate information about expected tornado potential before tornado outbreaks. 
We aimed to meet the expectation that research related to $\mathrm{D} / \mathrm{HoH}$ communities should incorporate the perspectives of culturally Deaf individuals (O'Connell and Lynch 2020); accordingly, this research relied on multiple Deaf perspectives (i.e., Deaf interpreters, Deaf participants, Deaf focus group) and professionals with expertise in related areas to aid in the development of our findings. Those who aim to conduct further research to improve accessibility for $\mathrm{D} / \mathrm{HoH}$ audiences should remain aware that it is important to incorporate the advice and expertise of Deaf professionals and Deaf community members in work related to this population.

Acknowledgments. This work was supported by the Vortex SE Program within the NOAA/OAR Office of Weather and Air Quality under Grant No. NA17OAR4590198. We also want to thank Richard Scott from WVUA in Tuscaloosa and Aaron Kubey and Richard Zabelski from the Department of Homeland Security and FEMA for their efforts in the creation of a television weather product using a CDI and ASL interpreter. Thank you to Emily Johannes for her interview transcription and coding efforts. We also would like to thank AIDB for hosting us and helping recruit participants for our interviews.

\section{REFERENCES}

Balluz, L., L. Schieve, T. Holmes, S. Kiezak, and J. Malilay, 2000: Predictors for people's response to a tornado warning: Arkansas, 1 March 1997. Disasters, 24, 71-77, Crossref.

Bélanger, N. N., and K. Rayner, 2015: What eye movements reveal about deaf readers. Current Directions in Psychological Science, 24, 220-226, Crossref.

Bennett, D. M., S. LaForce, C. Touzet, and K. Chiodo, 2018: American Sign Language \& emergency alerts: The relationship between language, disability, and accessible emergency messaging (Feedback from the field). International Journal of Mass Emergencies and Disasters, 36, 71-87.

Bourquin, E., M. Gasaway, B. Jordan, R. Pope., N. Rosensweig, and E. Spiers, 2006: Support service providers for people who are deaf-blind. American Association of the Deaf-Blind, $22 \mathrm{pp}$. [Available online at docplayer.net/1699849-Support-service-providersfor-people-who-are-deaf-blind.html.]
Burnham, D., J. Robert-Ribes, and R. Ellison, 1998: Why captions have to be on time. AVSP'98, Terrigal-Sydney, Australia, International Speech Communication Association, 153-156. [Available online at www.iscaspeech.org/archive open/archive papers/avsp98/ av98 153.pdf.]

Codina, C. J., O. Pascalis, H. A. Baseler, A. T. Levine, and D. Buckley, 2017: Peripheral visual reaction time is faster in deaf adults and British sign language interpreters than in hearing adults. Front. Psychol., 8, Crossref.

Coleman, T. A., and P. G. Dixon, 2014: An objective analysis of tornado risk in the United States. Wea. Forecasting, 29, 366-376, Crossref.

Crenshaw, K. W., 2017: On Intersectionality: Essential Writings. The New Press, 320 pp.

Eckert, R. C., 2010: Toward a theory of deaf ethnos: Deafnicity $\approx \mathrm{D} /$ deaf (hómaemon• homóglosson• homóthreskon). The Journal of Deaf Studies and Deaf Education, 15, 317-333, Crossref.

Ellcessor, E., 2019: Call if you can, text if you can't: A dismediation of U.S. emergency communication infrastructure. International Journal of Communication, 13, 4487-4506. [Available online at ijoc.org/index.php/ ijoc/article/view/11541.]

Ellis, K. N., L. R. Mason, K. N. Gassert, J. B. Elsner, and T. Fricker, 2018: Public perception of climatological tornado risk in Tennessee, USA. Int. J. Biometeorol., 62, 1557-1566, Crossref.

Emmorey, K., K. Winsler, K. J. Midgley, J. Grainger, and P. J. Holcomb, 2020: Neurophysiological correlates of frequency, concreteness, and iconicity in American Sign Language. Neurobiology of Language, 1, 249-267. $\underline{\text { Crossref. }}$

Engelman, A., S. L. Ivey, W. Tseng, D. Dahrouge, J. Brune, and L. Neuhauser, 2013: Responding to the deaf in disasters: establishing the need for systematic training for state-level emergency management agencies and community organizations. BMC Health Serv. Res., 13, Crossref. , and J. Deardorff, 2015: Cultural competence training for law enforcement responding to domestic violence emergencies with the deaf and hard of hearing. Health Promotion Practice, 17, 177-185, Crossref.

Gale, E., 2020: Collaborating with deaf adults in early intervention. Young Exceptional Children, Crossref.

Gensini, V. A., and H. E. Brooks, 2018: Spatial trends in United States tornado frequency. npj Clim. Atmos. Sci., 1, Crossref.

Griffin, D. J., 2018: American Sign Language and English bilingualism: Educators' perspectives on a bicultural education. International Journal of Bilingual Education and Bilingualism, Crossref.

Havelka, I., 2020: Video-mediated remote interpreting in healthcare. Babel, 66, 326-345, Crossref. 
Ivey, S. L., W. Tseng, D. Dahrouge, A. Engelman, L. Neuhauser, D. Huang, and S. Gurung, 2014: Assessment of state- and territorial-level preparedness capacity for serving deaf and hard-of-hearing populations in disasters. Public Health Reports, 129, 148-155, Crossref.

Leigh, I. W., 2009: A Lens on Deaf Identities: Perspectives on Deafness. Oxford University Press, 223 pp., Crossref. , J. F. Andrews, R. L. Harris, and T. Gonzalez Avila, 2020: Deaf Culture: Exploring Communities in the United States. 2nd ed., Plural Publishing, 384 pp.

Lin, F. R., 2011: Hearing loss prevalence in the United States. Arch. Intern. Med., 171,1851-1852. Crossref.

Liu, B. F., M. Egnoto, and J. R. Lim, 2019: How mobile home residents understand and respond to tornado warnings. Wea. Climate Soc., 11, 521-534, Crossref.

Luo, J., Z. Cong, and D. Liang, 2015: Number of warning information sources and decision making during tornadoes. Am. J. Prev. Med., 48, 334-337, Crossref.

Marschark, M., and H. E. T Knoors, 2020: Deaf studies in learning and cognition: A coming-of-age story. In The Oxford Handbook of Deaf Studies in Learning and Cognition, edited by M. Marschark and H. Knoors, Oxford University Press, 1-20, Crossref.

McKee, R., 2014: Breaking news: Sign language interpreters on television during natural disasters. Interpreting, 16, 107-130, Crossref.

McKee, M. M., M. K. Paasche-Orlow, P. C. Winters, K. Fiscella, P. Zazove, A. Sen, and T. Pearson, 2015: Assessing health literacy in deaf American Sign Language users. J. Health Commun., 20, 92-100, Crossref.

Moore, T. W., and T. A. DeBoer, 2019: A review and analysis of possible changes to the climatology of tornadoes in the United States. Progress in Physical Geography: Earth and Environment, 43, 365-390, Crossref.

MMWR, 2017: QuickStats: Percentage of adults aged $\geq 18$ years with any hearing loss, by state-National Health Interview Survey, 2014-2016. MMWR Morbidity and Mortality Weekly Report, 66, 1389, Crossref.

Murray, J. J., cited 2019: History of the Deaf. In Encyclopcedia Britannica. [Available online at www.britannica.com/ science/history-of-the-deaf.]

Neuhauser, L., S. L. Ivey, D. Huang, A. Engelman, W. Tseng, D. Dahrouge, S. Gurung, and M. Kealey, 2013: Availability and readability of emergency preparedness materials for deaf and hard-of-hearing and older adult populations: Issues and assessments. PLOS ONE, 8, Crossref.

NOAA, 2020a: The National Weather Service Works to Improve Weather Resilience within the Deaf Community [Available online at www.noaa.gov/ education/stories/national-weather-service-works-toimprove-weather-resilience-within-deaf-community.]
, 2020b: Weather Safety Information for Deaf and Hard of Hearing. [Available online at www.weather.gov/wrn/ dhh-safety.]

2020c: 'See a Flash, Dash Inside!' New Lightning Safety Slogan Rolls Out. [Available online at www. noaa.gov/stories/see-flash-dash-inside-new-lightningsafety-slogan-rolls-out?fbclid=IwAR2V4j4j47GyuHvM pJcM-uTJ 8 mZR4 u 5 kfkkx nhCw H1OT Ti2 VlrxpIdkh7g.]

O'Connell, N. P., and T. Lynch, 2020: Translating deaf culture: An ethnodrama. Qualitative Inquiry, 26, 411421, Crossref.

Pavani F., and D. Bottari, 2012: Visual abilities in individuals with profound deafness a critical review. In The Neural Bases of Multisensory Processes, edited by M. M. Murray and M. T. Wallace. CRC Press/Taylor \& Francis. [Available online at www.ncbi.nlm.nih.gov/books/ NBK92865/.]

Rotondi, L., M. Zuddas, and P. Rosati, 2018: A Facebook page created soon after the Amatrice earthquake provides a useful communication tool for deaf people, their relatives and caregivers. Enhancing CBRNE Safety \& Security: Proceedings of the SICC 2017 Conference, Rome, Italy, University of Rome Tor Vergata and the Health Safety Environmental Research Association Rome (HESAR), 425-431, Crossref.

Schultz, D. M., E. C. Gruntfest, M. H. Hayden, C. C. Benight, S. Drobot, and L. R. Barnes, 2010: Decision making by Austin, Texas, residents in hypothetical tornado scenarios. Wea. Climate Soc., 2, 249-254, Crossref.

Secora, K., and K. Emmorey, 2019: Social abilities and visual-spatial perspective-taking skill: Deaf signers and hearing nonsigners. The Journal of Deaf Studies and Deaf Education, 24, 201-213, Crossref.

Senkbeil, J. C., M. S. Rockman, and J. B. Mason, 2012: Shelter seeking plans of Tuscaloosa residents for a future tornado event. Wea. Climate Soc., 4, 159-171, Crossref. , K. N. Ellis, and J. R. Reed, 2019: The influence of tornado activity, impact, memory, and sentiment on tornado perception accuracy among college students. Atmosphere, 10, 732, Crossref.

Sherman-Morris, K., 2010: Tornado warning dissemination and response at a university campus. Nat. Hazards, 52, 623-638, Crossref.

,T. Pechacek, D. J. Griffin, and J. Senkbeil, 2020: Tornado warning awareness, information needs and the barriers to protective action of individuals who are blind. International Journal of Disaster Risk Reduction, 50, Crossref.

Singleton, J. L., and M. D. Tittle, 2000: Deaf parents and their hearing children. Journal of Deaf Studies and Deaf Education, 5, 221-236. Crossref. 
Smith-Warshaw, J., and P. Crume, 2020: Exploring the intersectionality of Deaf and Latinx cultures through service-learning. American Annals of the Deaf, 165, 2051, Crossref.

Stokes, C., and J. C. Senkbeil, 2016: Facebook and Twitter, communication and shelter, and the 2011 Tuscaloosa tornado. Disasters, 41, 194-208, Crossref.

Strader, S. M., K. Ash, E. Wagner, and C. Sherrod, 2019: Mobile home resident evacuation vulnerability and emergency medical service access during tornado events in the southeast United States. International Journal of Disaster Risk Reduction, 38, Crossref.

Walter, G., and R. Dirmyer, 2012: Number of persons who are deaf or hard of hearing: Rochester, NY, 2010. National Technical Institute for the Deaf. Rochester, NY. 11 pp. [Available online at www.dor.org/wp-content/ uploads/sites/7/2018/11/number_of persons_who_are deaf or hard of hearing.pdf.]

Walters, J. E., L. R. Mason, and K. N. Ellis, 2019: Examining patterns of intended response to tornado warnings among residents of Tennessee, United States, through a latent class analysis approach. International Journal of Disaster Risk Reduction, 34, 375-386, Crossref.

_ K. Kllis, and B. Winchester, 2020: Staying safe in a tornado: A qualitative inquiry into public knowledge, access, and response to tornado warnings. Wea. Forecasting, 35, 67-81, Crossref.

Wood, V. T., and R. A. Weisman, 2003: A hole in the weather warning system: Improving access to hazardous weather information for deaf and hard of hearing people. Bull. Amer. Meteor. Soc., 84, 187-194, Crossref. 